ago endowing computers with human, and even godlike, characteristics, but they have always lacked one essential ingredient-creativity, in other words, imagination, intuition and emotion. An exhibition opened this week at the Institute of Contemporary Arts in London that attempts to narrow this gap between the computer and the more humane arts. Jaisa Reichardt, who has worked since 1965 to organize and finance the exhibition, admits that it is not wholly successful in this attempt. "There are no heroic claims to be made," she says, "because computers have so far neither revolutionized music, nor art, nor poetry, in the same way that they revolutionized science." She stresses that the most important point of the exhibition is that "people who would have never put pencil to paper or brush to canvas have started to make images ... which approximate to what we call 'art' and put in public galleries".

It is just this point that many people will find disturbing as an extension of the already heated argument-when is an object considered "a work of art" ? Many of the pictures and graphics produced by computer programs do not raise this question either because they are simply two or three-dimensional projections of mathematical or physical phenomena, or because they are computerized transformations of a drawing or photograph, such as the picture of Marilyn Monroe (see illustration) that has been subjected to a

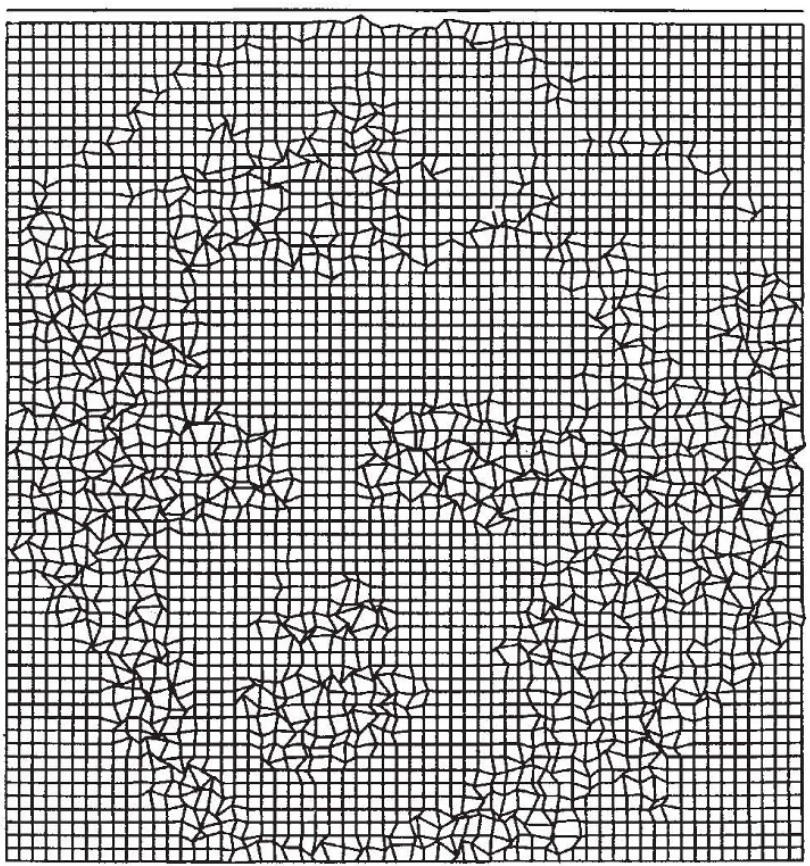

process of deforming. At the other extreme, the computer can be treated like any other medium, as a means of projecting an artist's concept. Several examples in the exhibition were produced by artists starting with an idea and then working out the program necessary to produce the desired effect. It is in the middle ground, where the program defines the basic set of parameters and leaves the various possibilities within them to chance, that the questions arise. A scientist at the Bell Telephone Laboratories, Michael Noll, produced a series of pictures based on an analysis of a black and white Piet Mondrian painting; when he showed both the original and one of the computer variations to a number of people, only 28 per cent correctly identified the Mondrian and 59 per cent preferred the computer picture. This does not mean to say that the computer could be considered more creative than Mondrian, but it does raise questions about aesthetics. Professor Dennis Gabor in an article in Encounter in 1960 said, "I sincerely hope that machines will never replace the creative artist, but in good conscience I cannot say that they never could".

In other creative fields, especially music and poetry, but also in sculpture and dance, the computer is being used extensively. Musicians especially are using it both to aid the composer in producing a score, which can then be played by the usual musical instruments, or to produce actual sounds in place of any other instruments and to any degree of complexity desired. The composing program allows the computer to make some of the choices-such as pitch, number of notes, intervals, duration-that the composer would normally make. In this way computer music is merely an extension of experimental works in the areas of electronic music and chance already being composed by such musicians as Karlheinz Stockhausen, John Cage and Cornelius Cardew.

Computers may not be creative in their own right, but this exhibition certainly shows that they can be used with artistic imagination, as this poem from the Manchester University Computer persuasively shows:

Darling sweetheart,/ You are my avid fellow feeling My affection curiously clings to your passionate wish My liking yearns for your heart

You are my wistful sympathy; my tender liking Yours beautifully, M.U.C.

\section{Costly Airbus}

THE three aviation ministers who met last week in Paris to discuss the future of the European airbus project seem to have taken a firm line. The project has been plunged into gloom by the recent announcement that the cost estimates were far wide of the mark. Instead of the total bill being something like $£ 190$ million, it has now increased to $£ 285$ million. The three governments have therefore agreed to postpone a decision on the airbus while further calculations are made. Over the next two months or so, the manufacturers will re-examine the costs of the project, in the hope either of reducing them to more manageable proportions, or of trying to produce a better aeroplane for the same cost. The ministers, from France, West Germany and Britain, asked the companies to produce the revised specifications by November. At the same time, the ministers produced a joint communiqué which urged the companies to produce an aircraft "even better adapted to the recent evolution of the market and to international competition".

Tt now seems very unlikely that the costs can be actually reduced, so the best hope is that a better acroplane can be put together for the same money. Most of the increase in cost has occurred on the airframe, which is principally the responsibility of Sud Aviation. It now seems that the design of the aircraft is more or less settled, and the companies involved 
claim that it is a very good design. The airlines which will have to buy it are naturally taking a more cautious line, and can hardly be expected to do more until the specification and costs are more clearly defined. And because the airlines put a high value on their independence, they are reluctant to make encouraging noises too soon.

There is also the possibility that Boeing may decide to enter the competition. Although Boeing has not yet made a definite statement of intention, it has worked on a design with some similarities to the European airbus, and this is enough to make the airlines hedge their bets until the position is clearer. Boeing has a loyal following among the airlines; British European Airways, for example, would have bought Boeing aircraft rather than the Hawker-Siddeley Trident if it had been allowed to. The delay in the airbus project gives Boeing a chance to get into the short-haul airbus market if it decides to. The best hope for the companies in the European airbus would be for Boeing to get so involved in the task of redesigning the American SST that it had no time to contem. plate more mundane aircraft.

Despite the uncertainty, the three firms involved in the European airbus have now formed a new company, to be called Airbus International. The task of the new company, which comprises Hawker Siddeley Aviation, Sud Aviation and Deutsche Airbus, will be to sell the airbus to the airlines, and to coordinate the activities of the three companies. Shares in the company have been taken up in proportion to the share of the cost of the project-37.5 per cent for France and Britain, and 25 per cent for West Germany. The chairman of the company is Dr Bernhardt Weinhardt, of Deutsche Airbus.

\section{Why Britain Withdrew}

Mr Edward SHort, the Secretary of State for Education and Science, is clearly not a man to shirk unpleasant duties. Last week he appeared before the Council for Scientific Policy to explain why the British Government had declined to accept its advice on the CERN $300 \mathrm{GeV}$ accelerator. Mr Short said that the Government had decided that it could not afford any new commitment. If the Government had signed the agreement, he said, it would not have been able to withdraw later, and the cost of the machine would probably increase. It felt that there were no short or medium term prospects of economic benefits from so costly a scheme and little chance of movement into industry of skilled manpower trained by participation in international high energy physies projects.

The Government had rejected the SRC proposal that the proportion of resources allocated to nuclear physics could be reduced by closing down obsolete national facilities and spending part of the money on the $300 \mathrm{GeV}$ machine, on the grounds that unless the CERN machine was built in Britain there would be no adequate facilities to train British scientists. Mr Short also said that this plan of the council assumed a substantial growth of the SRC budget over the next decade and the Government was not prepared to commit itself or its successor so far ahead. The minister assured the meeting that the decision was not the thin end of the wedge of Government interference in the disposal of the Research Council's funds and, presum- ably as a word of encouragement to the countries left in the scheme, he said the decision was not an attempt to discourage the project.

\section{Nuclear Estimates}

The European Nuclear Energy Agency has just made a courageous attempt to estimate the growth of nuclear power in Western Europe, and how different mixtures of reactors will affect the demand for uranium and for enrichment facilities. The attempt is courageous because estimates of this sort are notoriously tricky to do, and always likely to be overtaken by technical developments of one sort or another. The report, Illustrative Power Reactor Programmes (ENEA), covers itself by allowing generous margins for error-its low nuclear demand forecast for the year 2000 is less than half its high demand forecast-but the effort is nevertheless worthwhile.

By 1980 , the report estimates, the amount of electricity generated by nuclear power in Europe will have risen to $110 \mathrm{GW}\left(10^{9}\right.$ watts), from $10 \mathrm{GW}$ in 1970 and 40 GW in 1975 . Estimates after that are clearly more dubious, but the report suggests a demand of $392 \mathrm{GW}$ in $1990,800 \mathrm{GW}$ in 2000 and $1,350 \mathrm{GW}$ in 2010 . There are many ways in which this electricity could be generated, and the report considers some of

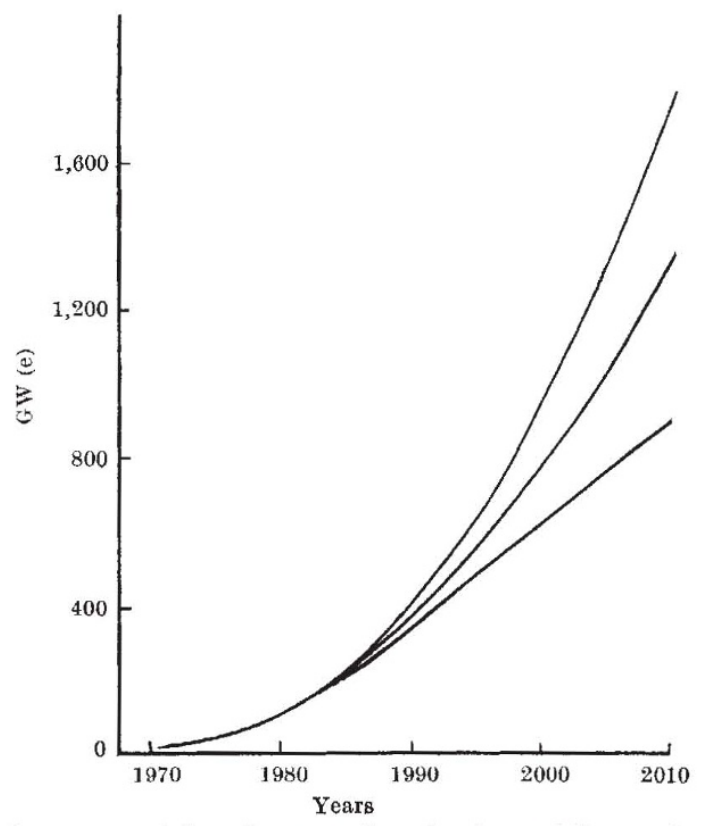

High, mean and low forecasts for the demand for nuclear power in Western Europe, 1970-2010. (OECD.)

the possible combinations of reactor types. The introduction of advanced thermal converters and fast breeders, certain to happen over the period under consideration, would be particularly important because of the effect it could be expected to have on uranium requirements. A nuclear power programme involving light water reactors only, for example, would by the year 2000 have used up nearly 2 million metric tons of uranium, and would be using it at an annual rate of 150,000 metric tons a year. A mixed system using light water reactors and fast breeders, on the other hand, would reduce the annual uranium requirements 